\title{
Relationship Between Caregivers' Burden of Schizophrenia Patient with Their Quality of Life in Indonesia
}

\author{
Rr Dian Tristiana - Bayu Triantoro - Hanik Endang Nihayati • \\ Ah Yusuf · Khatijah Lim Abdullah
}

Received: 4 April 2019/Accepted: 22 July 2019

(C) Springer Nature India Private Limited 2019

\begin{abstract}
This study aims to identify the relationship between caregiver burden of patients with schizophrenia and caregiver quality of life (QOL). A cross sectional study involving 222 caregivers patients with schizophrenia was conveniently recruited from the psychiatric clinic of a mental health hospital in Malang Indonesia. Caregiver Burden Inventory Scale and Schizophrenia Caregiver QOL was used to assess the level of burden and QOL among the caregivers respectively. Descriptive statistics was used to determine caregivers' socio-demographic characteristic and the level of caregivers' burden and QOL. Spearman Rho correlation test was conducted to determine the relationship of caregiver burden and caregiver QOL. About $59.6 \%$ of schizophrenia caregivers
\end{abstract}

R. D. Tristiana $(\bowtie) \cdot$ B. Triantoro - H. E. Nihayati ·

A. Yusuf

Faculty of Nursing, Universitas Airlangga, Surabaya, Indonesia

e-mail: diantristiana@fkp.unair.ac.id

B. Triantoro

e-mail: bayu.3antoro@gmail.com

H. E. Nihayati

e-mail: hanik-e-n@fkp.unair.ac.id

A. Yusuf

e-mail: ah-yusuf@fkp.unair.ac.id

\section{K. L. Abdullah}

Department of Nursing Science, Faculty of Medicine, University of Malaya, Kuala Lumpur, Malaysia

e-mail: katlim@um.edu.my experienced moderate to severe level of burden. The results showed that there was a significant, strong and negative relationship between the caregiver burden and QOL $(\mathrm{r}=-0.434, p<0.001)$. Most of the participants reported emotional burden and moderate QOL especially psychological and physical QOL, well-being, relationships with friends, and material burden. The findings indicated the higher the caregiver burden, the lower the QOL experienced by family caregivers of individuals with schizophrenia. It is necessary to improve the mental health nursing services for schizophrenia caregivers by providing mental health counseling, and developing support groups for them.

Keywords Caregiver burden - Caregiver quality of life $\cdot$ Schizophrenia

\section{Introduction}

Schizophrenia is a severe psychiatric disorder with an episodic and prolonged period that can lead to physical, psychological and social problems related to disease and the side effects of treatment [22]. World Health Organization reported that schizophrenia affects 21 million people worldwide [35]. Based on data from the Ministry of Health, schizophrenia in Indonesia have a prevalence of 1.7 per mil or around 400,000 people [27]. An individual with schizophrenia 
is unable to fulfill the expected roles within families and communities, experiencing difficulties and require continuous care and support from their families [3]. This condition has negatively impacted the families and increased stress and burden within their families.

Living with a relative with schizophrenia is stressful. Families who care for family members with schizophrenia experience financial, emotional, physical and social burdens that can cause stress $[32,36]$ and cause decreasing ability in providing care and support for other families [5] which can lead to failure in caring for the individual with schizophrenia at home [37].

Lack of knowledge about schizophrenia and lack of motivation to perform proper care for the individual with schizophrenia can increase the family burden [17]. Families often feel anxious and confused in caring for an individual with schizophrenia, especially when patients experience relapse [29]. In this study, a caregiver is defined as a family member, living with the schizophrenia patients for more than a year and has been closely involved in the patient's daily living activities, discussions, and care [20].

Previous studies showed that the care burden was associated with decreased quality of life (QOL) and had a significant impact on caregiver health and function. As a result of their burden, the caregiver was found to have a high prevalence of depression and anxiety symptoms [3]. Caregivers with high burdens have reported a decrease in QOL [22, 23]. Positive coping of schizophrenia caregiver is expected to reduce the care burden, which ultimately improves the caregiver's QOL as well as the QOL of the individual with schizophrenia [5]. A previous local study on the burden and QOL of schizophrenia patients caregiver in Indonesia found that gender, level of education and employment status are related to the QOL and nearly half of the caregivers experienced difficulties while taking care of the patients [34]. However, there are limited local studies on the relationship between caregivers' burden of schizophrenia patients' and caregivers' QOL in Indonesia. The caregiver burden and QOL might be different due to the change in the healthcare system especially change in universal coverage system in Indonesia in 2014, family dynamics and societal perceptions towards patients with schizophrenia in Indonesia. This study aimed to explore the relationship between schizophrenia caregiver burden and quality of life in Indonesia.

\section{Method}

\section{Study Design}

A descriptive cross-sectional study was conducted because the data collection is representative of what occurred at a fixed point of time.

\section{Study Setting}

This study was conducted in out-patients setting in one of the largest mental health hospitals in Indonesia, Sayyidiman Mental Health Hospital located in Malang. This mental health hospital provides 700 beds for in-patient ward. Data from out-patients ward in January-March 2017 revealed that there were 6165 visits of schizophrenia patients.

\section{Participants}

The sample size was calculated using an online OpenEpi application based on the estimated population of 500 people. A sample size of at least 218 participants was sufficient to achieve a significance level of 0.05 , a margin error of $5 \%$ and a $95 \%$ confidence interval but the researcher was able to recruit of 222 participants conveniently. Caregivers were recruited on the basis of the following criteria: family member as schizophrenia caregiver, age 18-60 years; and living with schizophrenia patients $\geq 1$ year. Those who were paid as caregivers were excluded from this study.

\section{Procedure}

The data collection process was carried out based on diagnostic data of schizophrenia patients in medical records who came for routine follow up to the outpatients department. Self-administered questionnaires were given to caregivers who met the inclusion criteria while they were waiting for the schizophrenia patients. Explanation about the purpose and the nature of the study was given before informed consent was signed by the caregivers. After informed consent was signed, questionnaire of demographic data, caregiver burden 
scale and caregiver QOL scale were given to the respondents to be filled. The researcher was present in order to clarify if needed.

\section{Instruments}

The questionnaires had three sections; Section A consisted of demographic characteristics of the caregiver (9 items). Section B consisted of the caregiver burden questionnaire: The Indonesian version of Zarit Burden Interview (ZBI 22) and section C consisted of caregiver QOL questionnaire: Schizophrenia Caregiver Quality of Life questionnaire (S-CGQoL).

The Indonesian version of the ZBI 22 questionnaire was developed by Zarit and Zarit (copyright 1980, 1983, 1990) [10]. The ZBI 22 was selected over other possible instruments because it provides a multidimensional assessment of burden. This instrument focused on the subjective burden and objective burden with an emotional component, physical health, social burden, and financial burden. This instrument comprised of 22 questions with five-point scale (never $=0$; rarely $=1 ; \quad$ sometimes $=2 ;$ quite frequently $=3$; nearly always $=4$ ). The score for each subscale ranges from 0 to 88 . A higher score indicates a greater burden. The tool interpretation was as follows: 0-20 indicates little or no burden, 21-40 indicates mild burden, and 41-60 indicates a moderate burden, while 61-88 indicates a severe burden.

The QOL of the caregiver was measured with Schizophrenia Caregiver Quality of Life questionnaire (S-CGQoL) [22], self-reported instrument. The instrument comprised of 25 questions with five-point scale (never $=4$; rarely $=3$; sometimes $=2$; quite frequently $=3$; nearly always $=0$ ). This instrument has seven dimensions: psychological and physical wellbeing; psychological burden and daily life; relationships with spouse; relationships with psychiatric team; relationships with family; relationships with friends; and material burden. Each dimension and the total index score is described as very poor $=0-20$; poor $=$ $21-40 ;$ moderate $=41-60 ;$ good $=61-80 ;$ and very good $=81-100[22]$.

A pilot study involving 15 participants was conducted to test the reliability of the instruments. Cronbach alpha of 0.93 and 0.90 was found for ZBI 22 and S-CGQoL respectively. Face validity was done by a panel of experts.
Ethical Clearance

This study has been approved by the ethical committee of Faculty of Nursing Universitas Airlangga (No. 560/KEPK dated November 10, 2017).

Statistical Analysis

The Statistical Package for Social Science (SPSS) version 16 was used for analysis. Descriptive statistics were performed using frequency counts and percentages for categorical variables while means, and the standard deviation was used for numerical variables. Normality test using Kolmogorov-Smirnov performed indicated $p<0.05$, thus non-parametric test was used. The rank correlation analysis (Spearman's rho) was performed to examine the relationship between caregiver burden and caregiver QOL. The level of statistical significance was set at $p<0.05$.

\section{Results}

Demographic Characteristic of Caregivers

The study included 222 caregivers aged 18-60 with a mean (SD) age of $44.05(9.61 \%)$ years. They were predominantly male caregivers $(68.9 \%)$ and mostly married $(87.8 \%)$. The most common caregivers' relationship with schizophrenia patients were in the form of parents (37.8\%) and siblings (32.9\%). Most of them had completed senior high school $(52.3 \%)$ with an average of income 1,723,648,653 (rupiah/month) (Table 1).

\section{Caregiver Burden}

The scores on the various domains of caregiver burden are given in Table 2. It was found that $8.6 \%(\mathrm{n}=19)$ of the caregivers had severe burden, $32 \%(n=71)$ of the caregivers had moderate burden, $32 \%(\mathrm{n}=71)$ of the caregivers had mild burden, and $27.5 \%(n=61)$ of the caregivers had little or no burden (Table 3 ). The total mean score was 35.05 (mild burden). The emotional burden is the highest burden with a mean (SD) of 1.67 (0.85) score as depicted in Table 3. 
Table 1 Sociodemographic profile of caregiver $(n=222)$

\begin{tabular}{|c|c|c|c|}
\hline Demographic & Frequency $(\%)$ & Caregiver burden $p$ values & Caregiver QOL $p$ values \\
\hline Sex & & 0.004 & 0.003 \\
\hline Male & $153(68.9)$ & & \\
\hline Female & $69(31.1)$ & & \\
\hline Marital status & & 0.017 & 0.045 \\
\hline Married & $195(87.8)$ & & \\
\hline Single & $21(9.5)$ & & \\
\hline Divorce & $6(2.7)$ & & \\
\hline Average of age (in years) (SD) & 44.05 & 0.228 & 0.268 \\
\hline Duration of care (years) & & 0.048 & 0.284 \\
\hline $1-2$ & $36(16.2)$ & & \\
\hline $2-5$ & $69(31.1)$ & & \\
\hline $5-10$ & $80(36)$ & & \\
\hline $10-15$ & $25(11.3)$ & & \\
\hline$>15$ & $12(5.4)$ & & \\
\hline Education level & & 0.171 & 0.186 \\
\hline Elementary school & $21(9.5)$ & & \\
\hline Junior high school & $62(27.9)$ & & \\
\hline Senior high school & $116(52.3)$ & & \\
\hline Bachelor degree & $23(10.4)$ & & \\
\hline \multicolumn{4}{|l|}{ Employment status } \\
\hline Employed & $208(93.7)$ & & \\
\hline Unemployed & $14(6.3)$ & & \\
\hline Average of income/salary (in rupiah/month) & 1723648,653 & 0.244 & 0.134 \\
\hline Relationship with patients & & 0.322 & 0.441 \\
\hline Parents & $84(37.8)$ & & \\
\hline Sibling & $73(32.9)$ & & \\
\hline Child & $16(7.2)$ & & \\
\hline Spouse & $33(14.9)$ & & \\
\hline Other: uncle/aunt, grandparents, sister-in-law & $16(7.3)$ & & \\
\hline \multicolumn{4}{|l|}{ Cost } \\
\hline Insurance & $201(90.5)$ & & \\
\hline No insurance & $21(9.5)$ & & \\
\hline
\end{tabular}

Table 2 Caregiver burden distribution

\begin{tabular}{lcl}
\hline Category & $\mathrm{N}(\%)$ & $\%$ \\
\hline little or no burden & $61(27.5)$ & 27.5 \\
mild burden & $71(32)$ & 32 \\
moderate burden & $71(32)$ & 32 \\
severe burden & $19(8.6)$ & 8.6 \\
$\mathrm{~N}$ & $222(100)$ & 100 \\
\hline
\end{tabular}

\section{Caregiver Quality of Life}

The caregivers experienced a moderate $(33.8 \%)$ and high $(33.3 \%)$ QOL. Only $15.3 \%(n=34)$ has a poor QOL (Table 4). The two domains namely: relationship with the psychiatric team and psychological burden and activity of daily living had the highest mean score of 3.26 (SD 0.72) and 2.57 (1.02) respectively (Table 5). 
Table 3 Caregiver burden detail

\begin{tabular}{lll}
\hline Variable & Mean & SD \\
\hline Emotional burden & 1.672 & 0.85 \\
Physical burden & 1 & 0.8 \\
Social burden & 1.4 & 1 \\
Financial burden & 2 & 1.1 \\
Total mean score & 35.5 & \\
\hline
\end{tabular}

Table 4 Caregiver quality of life distribution

\begin{tabular}{lll}
\hline Category & $\mathrm{N}(\%)$ & $\%$ \\
\hline Low & $34(15.3)$ & 15.3 \\
Moderate & $75(33.8)$ & 33.8 \\
High & $74(33.3)$ & 33.3 \\
Very high & $39(17.6)$ & 17.6 \\
\hline
\end{tabular}

Association Between Demographic Factors Caregiver Burden and Caregiver Quality of Life

Based on statistical analysis, demographic factors which correlated with caregiver burden were their gender $(p=0.004)$, marital status $(p=0.017$; $\mathrm{r}=0.161)$, and duration of care $(p=0.048$; $\mathrm{r}=0.133)$. Whereas, their age $(p=0.228)$, education level $(p=0.171)$, income $(0.244)$, and relationship with patients $(p=0.322)$ had no significant relationships with caregiver burden (Table 1).

Demographic factors which correlated with caregiver QOL were caregiver gender $(p=0.003)$ and marital status $(p=0.045 ; \quad r=0.135)$. Whereas,

Table 5 Caregiver quality of life detail

\begin{tabular}{lrl}
\hline Variable & Mean & SD \\
\hline Psychological and physical well being & 2.11 & 1.04 \\
Psychological burden and activity daily living & 2.57 & 1.02 \\
Relationship with spouse & 2.37 & 0.98 \\
Relationship with psychiatric team & 3.26 & 0.72 \\
Relationship with family & 2.54 & 0.95 \\
Relationship with friends & 2.19 & 1 \\
Material burden & 2.07 & 0.86 \\
Total mean score & 61.05 & \\
\hline
\end{tabular}

caregiver age $(p=0.268)$, caregiver education level ( $p=0.186)$, caregiver income $(p=0.134)$, relationship with patients $(p=0.441)$, and duration to care ( $p=0.284)$ had no significant relationship with caregiver QOL.

Association Between Caregiver Burden and Caregiver Quality of Life

Based on Spearman rho statistical analysis, caregivers burden was found to be inversely correlated to their QOL $(r=-0.434, p<0.001)$. The more severe a burden the poorer level of caregiver QOL.

\section{Discussion}

The caregiver demographic characteristics which significantly correlated with caregiver burden were their gender, marital status, and duration of care. Most of the caregivers in this study were male with mild burden and moderate burden. Previous study results showed that most of the caregivers' were males with mild to moderate burden [1]. The male caregiver tends to have less social pressure to care for relatives and had a lower burden [9] compared with a female caregiver. Most of the caregivers' were parents. Indonesian culture considers that the role and obligation of parents are to look after their children optimally. From this perspective, the male caregiver in this study who also had a role as a parent had no burden to moderate burden.

In regards to the demographic characteristics, correlates married male caregivers had better QOL. There are other studies that stated that married males caregivers reported significantly better QOL $[14,15]$. This might be due to the physical and emotional support of their spouses [15]. In addition, in this study, the majority of the caregivers are males who traditionally played the role of the head of a family. Their perceived burden may be viewed as part of their responsibilities as the head of a family.

The result showed that more than half of the caregivers had mild and moderate burden (64\%). A study from India showed that most caregivers experience moderate care, while a few others experience mild or severe burden $[13,36]$. A possible explanation for the findings may be due to the family structure in Indonesia. Family is the smallest unit of the 
community and members have respective roles including providing health care and giving care for the sick family member [7]. Family is a resource that is directly responsible for giving continuous care and preventing relapse of schizophrenia patients at home [8]. Most of the caregivers in this study are parents and male. The previous study stated that parents perceived to have bigger responsibility towards their children than other family members [25], and older male caregivers of schizophrenia patients had lower burden $[16,21]$.

In Indonesia, caring for family members with mental illness is performed by the family without hesitation, as providing care for the family is deeply rooted in their culture and arises "naturally" without conscious thought. The previous study found that caregiving was embedded in Asian life experience [19] and is closely related to responsibility when family members suffer from schizophrenia [11]. Thus, other family members in this study may also be involved in the care of their family member with schizophrenia. This shared responsibility in caring for schizophrenia patients might make the caregiver burden less severe.

Most of the participants reported having a financial burden. Although most participants had universal health coverage program from the Indonesian government which covered the treatment cost for schizophrenia patients, not all treatment cost is covered by the program. The transportation cost also can be a problem due to regular hospital visits for treatment. This is consistent with a study that showed treatment cost and transportation cost can affect the financial burden for the schizophrenia caregiver [31].

The highest mean score in this study was the emotional burden. This finding was in accordance with the previous study which stated that emotional burden is experienced at varying levels by schizophrenia patients caregiver [24]. Most of the participants in this study have been caring for schizophrenia patients for at least 5-10 years. The previous study found that the longer the duration of care, the higher the burden experienced by the caregiver [18].

The results of the study showed that half of the caregivers have poor to moderate QOL. This is consistent with the previous study conducted in India, France and Chile which found that caregiver QOL is low to moderate $[4,6,28,30]$.
Slightly more than half of the caregivers had a high QOL. A higher QOL is closely related to the various characteristics of the family caregiver demography. The results showed that most caregiver gender is male, are parents, have jobs, are married and educated. High QOL is related to the male family caregiver, who is a working father and has a high level of education [21]. Another study found that low education, living with many other family members, single or divorced and not working related to low QOL scores [12]. Father as head of a family is responsible for the fulfillment of the physical, psycho-social and financial needs in the family. Higher educational levels facilitate the caregiver in understanding about the disease, how to care, and prevent relapse. Appropriate response and adaptation to situations of parenting also affect the caregiver QOL.

Most of the caregivers reported low QOL especially in aspects of psychological and physical well-being, relationships with friends, and material burden. The previous study stated that older caregivers, low socioeconomic status, limited support networks might have poorer psychological and physical health than caregivers who are younger and have more economic and interpersonal resources [33]. In this study, the mean age of the caregiver was 44.5 years old. Older age is usually associated with impairments in the physical aspect which can cause the caring process to be more difficult [26]. The mean income of participants in this study was less than minimum regional wages (the lowest remuneration that employers can legally pay their workers) which means that they might have financial difficulties in caring for schizophrenia patients. The caregiver also reported having difficulties in making relationship with friends. The negative perception from society is still a problem for schizophrenia patients in Indonesia leading to fewer social contacts among the caregivers. This study showed that there is a significant relationship $p=0.00$ $(\alpha<0.05)$ with a strong negative directional relationship ( $r=-0.799)$ between the caregiver burden and caregiver QOL. It means that the higher the burden experienced by the caregiver, the lower the caregiver QOL. This result is consistent with previous studies which stated that caregiver burden is significantly related to the QOL with opposite direction study $[6,12,21,39]$. Caregivers with severe burden tend to experience poor QOL $[2,38]$. 
This study has limitations regarding the method used for data retrieval, namely the cross-sectional method. Burden and QOL are simultaneously assessed. There is generally no evidence of a temporal relationship between exposure and outcome.

\section{Conclusion and Recommendations}

Caregivers of schizophrenia patients reported financial and emotional burdens. Low QOL in the domains of psychological and physical well-being, relationships with friends, and material burden are most reported by the caregivers'.

This study provides information that schizophrenia caregiver burden and QOL are inversely correlated; the more severe a burden the poorer level of caregiver QOL. Health care professionals should collaborate with the schizophrenia caregiver to assess factors that affect their burden and QOL to find appropriate support and specific intervention to the schizophrenia caregiver.

The findings from this study draw the attention of healthcare providers to the possibility that caregivers may experience burden in caregiving for patients with schizophrenia condition and poor QOL. It is necessary to improve the mental nursing service for the schizophrenia caregiver by providing mental health counseling, develop a support group for the schizophrenia caregiver, and providing a home visit to reduce the travel cost borne by the family. It is also necessary to study the differences in caregiver QOL in extended families.

\section{Compliance with Ethical Standards}

Conflict of interest The authors declare that they have no conflict of interest.

\section{References}

1. Alzahrani SH, Fallata EO, Alabdulwahab MA, Alsafi WA, Bashawri J. Assessment of the burden on caregivers of patients with mental disorders in Jeddah, Saudi Arabia. BMC Psychiatry. 2017. https://doi.org/10.1186/s12888017-1368-1.

2. Awadalla AW, Ohaeri JU, Salih AA, Tawfiq AM. Subjective quality of life of community living sudanese psychiatric patients: comparison with family caregivers' impressions and control group. Qual Life Res. 2005;14(8):1855-67. https://doi.org/10.1007/s11136-005-4328-z.

3. Bademli K, Duman ZE. Effects of a family-to-family support program on the mental health and coping strategies of caregivers of adults with mental illness: a randomized controlled study. Arch Psychiatr Nurs. 2014;28(6):392-8. https://doi.org/10.1016/j.apnu.2014.08.011.

4. Caqueo-Urízar A, Alessandrini M, Urzúa A, Zendjidjian X, Boyer L, Williams DR. Caregiver's quality of life and its positive impact on symptomatology and quality of life of patients with schizophrenia. Health Qual Life Outcomes. 2017. https://doi.org/10.1186/s12955-017-0652-6.

5. Caqueo-Urízar A, Urzúa A, Jamett PR, Irarrazaval M. Objective and subjective burden in relatives of patients with schizophrenia and its influence on care relationships in Chile. Psychiatry Res. 2016;237:361-5. https://doi.org/10. 1016/j.psychres.2016.01.013.

6. Dalky H, Qandil A, Natour A, Janet M. Quality of life, stigma and burden perception among family caregivers and patients with psychiatric illnesses in Jordan. Community Ment Health J. 2017;53(3):266-74. https://doi.org/10.1007/ s10597-016-0028-0.

7. Efendi F, Makhfudli M. Keperawatan Kesehatan Komunitas Teori dan Praktik dalam Keperawatan. Jakarta: Salemba Medika; 2009.

8. Farkhah L, Suryani S, Hernawaty T. Faktor Caregiver dan Kekambuhan Klien Skizofrenia. Padjadjaran Nurs J. 2017. https://doi.org/10.24198/jkp.v5i1.348.g149.

9. Friedemann M-L, Buckwalter KC. Family caregiver role and burden related to gender and family relationships. J Fam Nurs. 2014;20(3):313-36. https://doi.org/10.1177/ 1074840714532715.

10. Hanzawa S, Tanaka G, Inadomi H, Urata M, Ohta Y. Burden and coping strategies in mothers of patients with schizophrenia in Japan. Psychiatry Clin Neurosci. 2008;62(3):256-63.

11. Hernandez M, Barrio C. Perceptions of subjective burden among latino families caring for a loved one with schizophrenia. Community Ment Health J. 2015;51(8):939-48. https://doi.org/10.1007/s10597-0159881-5.

12. Jeyagurunathan A, et al. Psychological status and quality of life among primary caregivers of individuals with mental illness: a hospital based study. Health Qual Life Outcomes. 2017;15(1):106. https://doi.org/10.1186/s12955-017-0676$\mathrm{y}$.

13. Kumar R, Saini R. Extent of burden and coping strategies among caregivers of mentally-ill patients. Nurs Midwifery Res J. 2012;8(4):274-84.

14. Lua P, Bakar Z. Health-related quality of life profiles among family caregivers of patients with schizophrenia. Fam Community Health. 2011;34:331-9.

15. Martin J, Padierna A, Aguirre U. Predictors of quality of life and caregiver burden among maternal and paternal Caregivers of patients with eating disorders. Psychiatry Res. 2013;210(3):1107-15.

16. Masa'Deh R. Perceived stress in family caregivers of individuals with mental illness. J Psychosoc Nurs Ment Health Serv. 2017;55(6):30-5. https://doi.org/10.3928/0279369520170519-04. 
17. Nihayati HE, Mukhalladah DA, Krisnana I. Pengalaman Keluarga Merawat Klien Gangguan Jiwa Pasca Pasung. Jurnal Ners. 2016;11(2):283-7. https://doi.org/10.20473/jn. V11I22016.283-287.

18. Özyeşil Z, Oluk A, Çakmak D. State and trait anxiety levels of load procedure giving care to elderly patients. Anatol J Psychiatr Nurs. 2014;15:39-44.

19. Pharr JR, Francis CD, Terry C, Clark MC. Culture, caregiving, and health: exploring the influence of culture on family caregiver experiences. ISRN Public Health. 2014. https://doi.org/10.1155/2014/689826.

20. Ravi S, Goud B, Archana M, Pius T, Pal A, John V. Burden among caregivers of mentally-ill patients: a rural community-based study community medicine. Int J Res Dev Health. 2013;1:29-34.

21. Ribé J, Salamero M, Pérez-Testor C, Mercadal J, Aguilera C, Cleris M. Quality of life in family caregivers of schizophrenia patients in Spain: caregiver characteristics, caregiving burden, family functioning, and social and professional support. Int $\mathbf{J}$ Psychiatry Clin Pract. 2017;22(1):25-33. https://doi.org/10.1080/13651501.2017. 1360500 .

22. Richieri R, Boyer L, Reine G, Loundou A, Auquier P, Lancon C, Simeoni MC. The Schizophrenia Caregiver Quality of Life questionnaire (S-CGQoL): development and validation of an instrument to measure quality of life of caregivers of individuals with schizophrenia. Schizophr Res. 2011;126(1-3):192-201. https://doi.org/10.1016/j. schres.2010.08.037.

23. Rofail D, Regnault A, le Scouiller S, Lambert J, Zarit SH. Assessing the impact on caregivers of patients with schizophrenia: psychometric validation of the Schizophrenia Caregiver Questionnaire (SCQ). BMC Psychiatry. 2016;16(1):245. https://doi.org/10.1186/s12888-016-09511.

24. Sagut P, Çetinkaya Duman Z. Comparison of caregiver burden in first episode versus chronic psychosis. Arch Psychiatr Nurs. 2016;30(6):768-73. https://doi.org/10. 1016/j.apnu.2016.07.011.

25. Sanjaya U. Hubungan Antara Caregiver Burden Dengan Kualitas Hidup Family Caregiver Pasien Gangguan Mental Berat yang Mengalami Pemasungan di Kabupaten Ponorogo. Surabaya: Universitas Airlangga; 2016.

26. Shah AJ, Wadoo O, Latoo J. Psychological distress in carers of people with mental disorders. $\mathrm{Br} \mathrm{J}$ Med Pract. 2010;3(3):327.

27. Soebiantoro J. Pengaruh Edukasi Kesehatan Mental Intensif Terhadap Stigma pada Pengguna Layanan Kesehatan Mental. Jurnal Psikologi Dan Kesehatan Mental. 2017;52:1-14. https://doi.org/10.20473/jpkm.v2i12017.121.

28. Stanley S, Balakrishnan S, Ilangovan S. Psychological distress, perceived burden and quality of life in caregivers of persons with schizophrenia. J Ment Health.
2017;26(2):134-41. https://doi.org/10.1080/09638237. 2016.1276537.

29. Suhita BM. The adaptation model of caregiver in treating family members with schizophrenia in Kediri East Java. Jurnal Ners. 2017;12(37):74-80.

30. Testart J, Richieri R, Caqueo-Urízar A, Lancon C, Auquier P, Boyer L. Quality of life and other outcome measures in caregivers of patients with schizophrenia. Expert Rev Pharmacoecon Outcomes Res. 2013;13(5):641-9. https:// doi.org/10.1586/14737167.2013.838022.

31. Tristiana RD, Yusuf A, Fitryasari R, Wahyuni SD, Nihayati HE. Perceived barriers on mental health services by the family of patients with mental illness. Int J Nurs Sci. 2018;5(1):63-7. https://doi.org/10.1016/j.ijnss.2017.12. 003.

32. Vania IW, Dewi KS. Hubungan Antara Dukungan Sosial Dengan Psychological Well-Being Caregiver Penderita Gangguan Skizofrenia. Skripsi: Universitas Airlangga; 2014.

33. Vitaliano P, Zhang J, Scanlan J. Is caregiving hazardous to one's physical health? A meta-analysis. Psychol Bull. 2003;129(6):946-72.

34. Winahyu, K. M., Hemchayat, M., \& Charoensuk, S. (2014). The Relationship between characteristic of caregivers and quality of life among family caregivers of patients with schizophrenia in Indonesia. Retrieved from https://www. researchgate.net/publication/314759039_The_ Relationships_between_Characteristics_of_Caregivers_ and_Quality_of_Life_of_Family_Caregivers_of_Patients_ with_Schizophrenia_in_Indonesia. Accessed Feb 2019.

35. World Health Organization. (2015). Mental health. Retrieved March 2, 2019, from https://www.who.int/ mental_health/management/schizophrenia/en/.

36. Yu Y, Liu Z, Tang B, Zhao M, Liu X, Xiao S. Reported family burden of schizophrenia patients in rural China. PLoS ONE. 2017. https://doi.org/10.1371/journal.pone. 0179425.

37. Yusuf A, Putra ST, Probowati Y. Peningkatan Coping Kelurga Dalam Merawat Pasien Gangguan Jiwa Melalui Terapi Spiritual Direction, Obedience Dan Acceptance (Doa). Jurnal Ners. 2012;7(2):198-202.

38. Zahid MA, Ohaeri JU. Relationship of family caregiver burden with quality of care and psychopathology in a sample of Arab subjects with schizophrenia. BMC Psychiatry. 2010. https://doi.org/10.1186/1471-244X-10-71.

39. Zhou Y, et al. Effect of living with patients on caregiver burden of individual with schizophrenia in China. Psychiatry Res. 2016;245:230-7. https://doi.org/10.1016/j. psychres.2016.08.046.

Publisher's Note Springer Nature remains neutral with regard to jurisdictional claims in published maps and institutional affiliations. 